\title{
Are free anti-tuberculosis drugs enough? An empirical study from three cities in China

\author{
Shanquan Chen ${ }^{1}$, Hui Zhang ${ }^{2,8^{*}}$, Yao Pan ${ }^{3}$, Qian Long ${ }^{4,5}$, Li Xiang ${ }^{6}$, Lan Yao ${ }^{6}$ and Henry Lucas ${ }^{7}$
}

\begin{abstract}
Background: Tuberculosis (TB) patients in China still face a number of barriers in seeking diagnosis and treatment. There is evidence that the economic burden on TB patients and their households discourages treatment compliance.

Methods: A cross-sectional study was conducted in three cities of China. Patients were selected using probability proportional to size (PPS) cluster sampling of rural townships or urban streets, followed by list sampling from a patient register. Data were collected using a questionnaire survey, key informant interviews and focus group discussions with TB patients to gain an understanding of the economic burden of TB and implications of this burden for treatment compliance.
\end{abstract}

Results: A total of 797 TB patients were surveyed, of which 60 were interviewed in-depth following the survey. More than half had catastrophic health expenditure. TB patients with higher household incomes were less likely to report non-compliance (OR 0.355, $95 \% \mathrm{Cl} 0.140-0.830$ ) and patients who felt that the economic burden relating to TB treatment was high more likely to report non-compliance (OR 3.650, 95 \% Cl 1.278-12.346). Those who had high costs for transportation, lodging and food were also more likely to report non-compliance (OR 4.150, $95 \% \mathrm{Cl}$ 1.804-21.999). The findings from the qualitative studies supported those from the survey.

Conclusion: The economic burden associated with seeking diagnosis and treatment remains a barrier for TB patients in China. Reducing the cost of treatment and giving patients subsidies for transportation, lodging and food is likely to improve treatment compliance. Improving doctors' salary system to cut off the revenue-oriented incentive, and expanding current insurance's coverage can be helpful to reduce patients' actual burden or anticipated burden. Future research on this issue is needed.

Keywords: Tuberculosis, Economic burden, Catastrophic expenditure, Compliance, China

\section{Multilingual abstracts}

Please see Additional file 1 for translations of the abstract into the six official working languages of the United Nations.

\section{Background}

Tuberculosis (TB) remains the most important infectious disease worldwide. Its etiological agent, Mycobacterium tuberculosis, infects one-third of the world population and it accounted for some 1.5 million deaths in 2013 according to WHO estimates [1]. China accounted for $11 \%$ of global TB cases in 2013. It ranked fifth in terms of the epidemiologic burden of $\mathrm{TB}$, with an incidence rate of

\footnotetext{
* Correspondence: zhanghui@chinatb.org

${ }^{2}$ National Center for TB Control and Prevention, China CDC, Beijing, PR China

${ }^{8}$ Chinese Center for Disease Control and Prevention, Beijing, PR China

Full list of author information is available at the end of the article
}

70 per 100,000 , a prevalence rate of 94 per 100,000 and an estimated 3.0 deaths per 100,000 attributed to TB in 2013 [1]. Attaining WHO's end TB strategy, zero deaths, disease, and suffering due to TB by 2035 , will be a major challenge [2]. Non-compliance with treatment remains a central concern [3-6]. The direct observation of treatment (DOT) approach has proved effective, but, as in many countries, considerable proportion of non-compliant patients exist [6-12].

Studies indicated that education level, marital status, employment, and lack of $\mathrm{TB}$ and its treatment related knowledge were important reasons for non-compliance $[8,9,13-15]$. A number of studies also assessed related costs and found that a high economic burden is associated with poor treatment compliance [16-21].

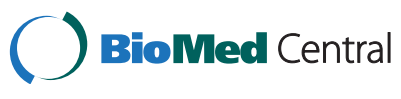

(c) 2015 Chen et al. Open Access This article is distributed under the terms of the Creative Commons Attribution 4.0 International License (http://creativecommons.org/licenses/by/4.0/), which permits unrestricted use, distribution, and reproduction in any medium, provided you give appropriate credit to the original author(s) and the source, provide a link to the Creative Commons license, and indicate if changes were made. The Creative Commons Public Domain Dedication waiver (http://creativecommons.org/publicdomain/zero/1.0/) applies to the data made available in this article, unless otherwise stated. 
To reduce the financial burden on and barriers to patients to facilitate seeking essential healthcare, a "free-TB service policy" has been implemented [9, 14, 16, 21, 22]. Under this policy, tuberculosis suspects are provided a free diagnosis and anti-tuberculosis treatment, including designated first-line TB drugs (6 months for new patients, 8 months if previously treated), chest X-ray examination for the first and last months, and sputum smear test $[16,21,23-25]$. Going with this policy, there are three service model: dispensary model, specialist model, integrated model [26]. The dispensary model is the most prevalent model. A TB dispensary is usually a department of Centre for Disease Control (CDC), with free treatment is only provided in this place. General hospitals are just responsible for referring TB suspects to dispensaries, and usually are supposed should not treat TB patients, unless severe or complicated cases. The specialist model is similar to dispensary model, with severe TB cases should only be treated in the specialist hospital, but treatment cost in specialist hospital is not covered by the free treatment policy. The integrated model is a new development, with the most popular general hospital in the district, usually called as TB designated hospital, provides TB treatment. TB dispensary continues to provide related service but just limited in training, mass education and case supervision, and should report and ensure referred TB suspects arrived in the designated hospital. Expenditure beyond the "free-TB service policy" was supposed to be covered by insurance. In china, health care system is bifurcated in nature between rural and urban areas [27], and TB patients mainly covered by government-led complementary insurance programs: the Urban Employee Basic Medical Insurance (UEBMI), designed exclusively for urban worker; the Urban Resident Basic Medical Insurance (URBMI), designed for urban residents without formal employment; the New Cooperative Medical Scheme (NCMS), designed for rural population.

Despite the free policy and the cover of insurance, the medical and non-medical costs incurred by TB patients and their households are still substantial [16, 28-32]. The phenomenon that requesting repeated investigation, including blood tests, X-rays and even CT test, and prescribing liver protection and ancillary drugs is not uncommon [10, 16, 21, 25, 33].

Several studies have also found that the anticipation of a high economic burden and concern with 'sunk costs' can affect patient decisions [9, 34-38]. Some patients may have poor compliance because they expect that the overall cost of treatment will be high even though their actual out-of-pocket payments have been relatively limited. Others who are facing serious financial difficulties may persevere with treatment because of the considerable investment in care already undertaken: the sunk cost effect. The observation of such complex relationships between economic burden and compliance emphasizes the need for a combination of qualitative and quantitative approaches. However, previous studies have generally adopted one approach. The primary objective of this paper is systematic research this problem through a mixed method.

Another gap is that previous studies usually focus on the direct medical cost. Few studies involve with direct non-medical and indirect costs. For certified low income and unemployed patients, just transportation cost can account for a considerable proportion of their annual household income. How about the relationship between economic burden incurred by direct non-medical and indirect costs and treatment compliance? The second objective of this paper is to fill this gap, and to examine whether and to what extent this burden affects patient treatment compliance.

\section{Methods}

\section{Study setting}

Since 2009, the Bill \& Melinda Gates Foundation, one of which efforts in China is fighting HIV/AIDS and tuberculosis (TB), in collaboration with the National Health and Family Planning Commission of the People's Republic of China (NHPFC), known as the Ministry of Health before March 2013, and China CDC, has developed and implemented an innovative program on TB control and prevention in China. Here we analyze data from a baseline survey in the three cities where the program was implemented: Zhengjiang City, Jiangsu Province; Yichang City, Hubei Province; and Hanzhong City, Shaanxi Province. They are located in the Eastern, Middle and Western Regions of China respectively, with a GDP per capital 73947 RMB, 56265 RMB, and 16935 RMB.

In 2012, the amount of registered TB patients in Zhengjiang, Hanzhong, and Yichang is 1768, 2336, and 3437 , respectively, with an estimated non-compliance rate, caused by economic burden, $3.0 \%, 3.3 \%$ and $5.7 \%$. The primary service model is the integrated model. Tuberculosis suspects are provided a free diagnosis and anti-tuberculosis treatment, including designated first-line TB drugs (6 months for new patients, 8 months if previously treated), chest X-ray examination in the first and last months, and sputum smear test. The first-line TB drugs are isoniazid, rifampicin, rifampicin and butyl, pyrazinamide, ethambutol and streptomycin, and patients are requested to take tests and bring back their drugs every one or two month.

\section{Study sampling}

Due to china's large population and area, Chinese administration unit have consisted of several levels, mainly including provincial, prefectural, county, township, village. Prefectural level's city, for instance Zhengjiang City, can also be divided into district, and further into street. To sample adapt to China's administration unit, Probability- 
Proportional-to-Size Sampling (PPS) was adopted [39, 40]. Using selected key indicators, the required sample size per city was calculated to be 264 cases. This was rounded up to 270. As economic situation, to some extent, can stand for one place's healthy development condition and people's cognition of health. One county or district was randomly selected in each of three GDP per capita categories (high, middle and low). Six townships or streets were then sampled using PPS in each county or district and TB cases randomly sampled from the notification list. In total, 797 TB patients were surveyed (263 in Zhenjiang, 270 in Hanzhong and 264 in Yichang) and 60 of these were selected for in-depth interview.

\section{Data collection}

Data collection employed a combination of both quantitative and qualitative methods. A survey questionnaire was developed which collected data on demographic and socioeconomic information, patient diagnostic and treatment pathways and history, direct health service expenditures, indirect costs (transport and accommodation costs, associated additional household costs and household income foregone), borrowing resulting from illness, and compliance during treatment. We identified non-compliant patients as those who interrupted or stopped treatment (if not because of any adverse reactions) or refused treatment. The questionnaire and survey procedures were tested in a pilot study carried out in one project site. The survey was conducted by university students from Huazhong University of Science and Technology (Yichang), Xi'an Jiaotong University (Hanzhong) and Nanjing Medical University (Zhejiang). These students received appropriate training on interview skills and the contents of the questionnaire.

Quantitative data were self-reported and self-recalled. Household income was the aggregate of household income from production, wage incomes of household members, transfer income (pensions, remittances, welfare) and property income (interest, rent) [41-45]. Household income foregone was calculated by days unable to work since the onset of TB multiplied by the average reported lost income per day $[29,46]$. The collection of direct and indirect costs followed the approach of Umar et al. [29].

Focus Group Discussions (FGDs) were held with TB patients. Each county organized one FGD with six to eight TB patients. A total of nine FGDs were conducted by university faculty members. All FGDs were tape recorded with the permission of participants. The inclusion criterion was simply defined in terms of patients with recent TB treatment experience who could clearly communicate their thoughts. As we identified patients from a list of TB patients compiled at the time that each patient began their TB regimen, there "recent" means six months or eight months as the standard course is six months for new cases and eight months for relapse cases. Each group was intended to reflect diversity in terms of gender, agegroup and socio-economic status. Patients were selected with the help of the local CDC officials and informed about the study and its purpose. 60 of patients were selected, including 18 in Zhenjiang, 19 in Hanzhong and 23 in Yichang. The interviewer used a semi-structured interview guide with questions concerning direct health service expenditures, travel and subsistence costs, the affordability of TB services, and the reasons why treatment might be refused or interrupted.

\section{Major definitions}

We define:

- OOP: out-of-pocket payment

- TOOP: total out-of-pocket payment, including direct medical costs, direct non-medical costs, and indirect costs, as a percent of household income;

- OOP2: out-of-pocket payment for diagnosis and treatment as a percent of household income;

- TLF: travel, lodging and food costs as a percent of household income;

- Irishr: income foregone due to the illness as a percent of household income;

- DSC: dietary supplement costs as a percent of household income;

- Ethel: patients' subjective assessment whether TB causes a heavy burden to their family;

- Dietary supplement costs are expenditures on additional food, vitamins. During the period following diagnosis. Travel and subsistence costs are expenditures on travel, accommodation and food while seeking diagnosis and during treatment.

TOOP and OOP2 were defined as "catastrophic" if they equaled or exceeded $10 \%[47,48]$. There is no generally accepted standard for excessive expenditure on TLF, IncFor and DSC. In this study, we defined TLF, IncFor and DSC as "heavy" for cases in which they equaled or exceeded their median values.

\section{Data management and analysis}

Both the quantitative and qualitative data were entered into relational databases using the double-entry options of Epidata 3.1 and Nvivo 10, and analyzed with SPSS 20.0 and Nvivo10.

Following descriptive analysis, we used logistic regression to examine whether treatment compliance was associated with the extent of the economic burden. Taking account of the small sample of non-compliance patients, the bootstrap approach was adopted. Economic burden indicators are shown in Table 3. Additional variables included EcoBur and the household income level. Potential confounding variables are presented in Table 1. We 
Table 1 Social-economic characteristics of TB patients

\begin{tabular}{|c|c|c|c|}
\hline & Compliant $(n=765)$ & Non-compliant $(n=32)$ & $P$ value* \\
\hline Sex (female) & $193(25.23)$ & $10(31.25)$ & 0.444 \\
\hline Age & $56.07(15.02)$ & $60.09(9.72)$ & $0.031 * *$ \\
\hline \multicolumn{4}{|l|}{ Residence } \\
\hline Rural & 704(92.03) & $32(100)$ & \multirow[t]{3}{*}{0.225} \\
\hline Urban & $59(7.71)$ & $0(0)$ & \\
\hline Rural- Urban continuum & $2(0.26)$ & $0(1)$ & \\
\hline \multicolumn{4}{|l|}{ Education } \\
\hline Primary school and lower & $398(52.03)$ & $27(84.38)$ & \multirow[t]{3}{*}{0.002} \\
\hline Secondary school or at the same level & $265(34.64)$ & $4(12.50)$ & \\
\hline High school and higher & 102(13.33) & $0(0)$ & \\
\hline \multicolumn{4}{|l|}{ Employment } \\
\hline Employment & 408(53.33) & 15(46.88) & \multirow[t]{2}{*}{0.473} \\
\hline Unemployment & $357(46.67)$ & 17(53.12) & \\
\hline \multicolumn{4}{|l|}{ Health insurance } \\
\hline UEBMI & $53(6.93)$ & $0(0)$ & \multirow[t]{3}{*}{0.287} \\
\hline NCMS & 679(88.76) & 30(93.75) & \\
\hline URBMI & $21(2.75)$ & $1(3.12)$ & \\
\hline \multicolumn{4}{|l|}{ Household income } \\
\hline Low (lowest 25) & 184(24.31) & $16(51.61)$ & \multirow[t]{3}{*}{0.003} \\
\hline Middle (medium 50) & $372(49.14)$ & 10(32.26) & \\
\hline High (top 25) & $201(26.55)$ & $5(16.13)$ & \\
\hline \multicolumn{4}{|l|}{ EcoBur } \\
\hline Low & $80(10.47)$ & $0(0)$ & \multirow[t]{3}{*}{$<0.001$} \\
\hline General & 289(37.83) & $1(3.12)$ & \\
\hline High & 395(51.70) & $31(96.88)$ & \\
\hline
\end{tabular}

Data are number of patients (\%) or mean (SD). Several factors total number is not equal to 764 or 32 , due to the existence of missing value. ${ }^{*}$ This value calculated by chi-square test. ${ }^{* *}$ This value calculated by t-test

first identified factors that might be expected to vary substantially between compliant and non-compliant patients and then included them in analysis using forward selection [49].

Almost everyone was covered by one of the health insurance schemes, with urban patients usually subscribing to UEBMI or URBMI and rural patients to NCMS. As indicated in Table 1, at the bivariate level we cannot reject the hypothesis that insurance type did not vary significantly between compliant and non-compliant patients. Because of its policy relevance we retain this variable in regression model. Finally, Age, UEBMI, URBMI and Education were therefore included in the regression model. As there were substantial correlations between all the economic burden variables, we fitted a separate model for each.

The data is self-reported and it is highly likely that there will be recall bias. To reduce the impact of data errors and exclude the influence of extreme values we transformed the continuous variables to generate dichotomous or ordinal forms. As this results in a substantial loss of information we also present findings using the original variables.

The qualitative data were analyzed using the 'framework approach' [50]. The framework was developed based on a topic guide, with categories emerging from an initial analysis of the transcripts and applied to the data to identify themes. All qualitative data were coded, sorted and classified in terms of this framework. Charting was used to identify common or divergent perceptions and explanations were developed. The Nvivo 10 software package was used to manage the data. All analysis was conducted in Chinese to avoid translation issues. The final results, including the major themes and verbatim quotes were then translated into English.

\section{Ethics statement}

The Ethics Committee of China CDC gave final approval for this study (code: 201307). Written informed consent was obtained from all participants involved in the study. The ethics committee approved this procedure. 


\section{Results}

Demographic, education, and household income characteristics of study subjects

Table 1 shows the patient characteristics including their demographic and economic status. There were almost three times as many males as females. Most patients lived in rural areas and participated in the NCMS. Around $52 \%$ percent had only primary education and just under $47 \%$ were unemployed. Almost $52 \%$ considered TB as a heavy economic burden on their family. Only 32 patients reported poor compliance. Age, level of education and level of household income were significantly different between compliant and non-compliant patients.

Medical expenditure and economic burden of TB patients Table 2 shows the medical expenditures of TB patients. The average total expenditure on diagnosis and treatint for non-compliant patients is 17597 RMB (median 8400 $\mathrm{RMB}$ ), and for compliant patients is $10146 \mathrm{RMB}$ (median $5225 \mathrm{RMB}$ ). After reimbursed by insurance, the average OOP payment for diagnosis and treatment is $11164 \mathrm{RMB}$ (median $4100 \mathrm{RMB}$ ) for non-compliant patients, and 7154 RMB (median 4000 RMB) for compliant patients. For noncompliant patients the average transportation cost and lodging and food costs is $247 \mathrm{RMB}$ (median 164 RMB) and 881 RMB (median265 RMB), respectively, and for compliant patients the same costs is $251 \mathrm{RMB}$ (median $114 \mathrm{RMB}$ ) and $526 \mathrm{RMB}$ (median120 RMB), respectively. Compared with non-compliant patients, compliant patients' average income reduction due to missed work is higher, with 385 RMB (median 0 RMB) VS 176 RMB (median 0 RMB), and the similar result for dietary supplement costs with 305 RMB (median 250 RMB) VS 289 RMB (median 200 RMB). Tested by nonparametric test, the foregoing results don't have a significant difference between compliant and noncompliant TB patients.

Table 3 shows the economic burden on TB patients. More than half had catastrophic health expenditure (TOOP $\geq 10 \%$ ). The economic burden caused by OOP2 was also heavy. Nearly half of patients faced a heavy economic burden due to TLF or DSC. Unexpectedly, the economic impact of income foregone was very limited compared with the results from other studies [17, 29]. It is possible that this concept was not well understood by respondents. The aforementioned burden generally had a higher proportion of those who were non-compliant, except for the burden caused by IncFor, and TOOP and TLF were significantly different between compliant and noncompliant patients. Using the unstratified continuous variables produced similar results (Table 4), except in the case of DSC, which became significantly different between compliant and non-compliant patients.

The qualitative findings indicate that while basic TB drugs are provided free of charge, the costs of examinations, tests and adjuvant drugs can be substantial. There may also be overuse of CT scans and chest X-rays. This is illustrated in the following responses:

"Within a month, I had two CT scans and a chest X-ray" "...the cost is high, because of other checks, (such as) CT scans."

"...drugs are free, but the examination fees will cost more than 230 (RMB) per month"

"...some drugs are free, but examination fees and other adjuvant drug fees are higher (than free drugs would have cost)."

The qualitative results also show that, for longer courses of treatment, transport, lodging and food costs can be considerable:

Table 2 Direct and indirect costs of TB

\begin{tabular}{|c|c|c|c|c|c|}
\hline & \multicolumn{2}{|c|}{ Compliant } & \multicolumn{2}{|c|}{ Non-compliant } & \multirow[t]{2}{*}{$P$ value } \\
\hline & $\overline{M e a n}$ & Median [IQR] & $\overline{M e a n}$ & Median [IQR] & \\
\hline Total costs on diagnosis and treatment & 10146 & $5225[2500-11638]$ & 17597 & $8400[3000-30000]$ & 0.084 \\
\hline OOP payment for diagnosis and treatment & 7154 & $4000[2000-8000]$ & 11164 & $4100[2500-11000]$ & 0.356 \\
\hline Transportation cost (including companion members) & 251 & $114[32-280]$ & 247 & $164[39-365]$ & 0.266 \\
\hline Lodging and food costs (including companion members) & 526 & $120[0-640]$ & 881 & $265[54-753]$ & 0.248 \\
\hline Income reduction due to missed work days/hours & 385 & $0[0]$ & 176 & $0[0]$ & 0.320 \\
\hline \multicolumn{6}{|l|}{ (including companion members) } \\
\hline Dietary supplement costs & 305 & $250[120-400]$ & 289 & $200[200-500]$ & 0.899 \\
\hline Sold & 4083 & $2750[1500-8000]$ & 6000 & $6000[6000-6000]$ & - \\
\hline Borrow & 10586 & $5000[3000-15000]$ & 12515 & $4000[1500-20000]$ & - \\
\hline
\end{tabular}

Data are mean and median (IQR)

*This value calculated by nonparametric test 
Table 3 Direct and indirect costs as \% of household income of TB patients

\begin{tabular}{cccc}
\hline & Compliant $(n=765)$ & Non-compliant $(n=32)$ & $P$ value $^{*}$ \\
\hline TOOP $(n=737)$ & & & \\
Heavy $(=1)$ & $479(67.56)$ & $24(85.71)$ & 0.043 \\
OOP2 $(n=758)$ & & & \\
Heavy $(=1)$ & $427(58.41)$ & $20(74.07)$ & 0.104 \\
TLF $(n=775)$ & & & 0.001 \\
Heavy $(=1)$ & $368(49.20)$ & $22(81.48)$ & \\
IncFor $(n=789)$ & & & 0.763 \\
Heavy $(=1)$ & $78(10.30)$ & $2(6.25)$ & \\
DSC $(n=521)$ & & & 0.188 \\
Heavy $(=1)$ & $274(53.52)$ & $7(77.28)$ & \\
\hline
\end{tabular}

Data are number of patients (\%). TOOP and OOP2 were defined as "catastrophic" or "heavy" if they equaled or exceeded $10 \%$, and TLF, IncFor and CDS were defined as "heavy" if it equaled to or exceeded its median.* This value calculated by chi-square test

"Treatment time is long, (needing) eight or nine months... travel (cost) alone is high."

"(Transportation, lodging and food costs) will probably be more than 1000 (RMB). Almost 10000 (RMB) a year."

"...travel cost? Thousands of RMBs. (About) three or four thousands."

"...like me, come here every month. (Every time I needed) at least 300 (RMB). Round-trip travel expenses will be at least 100 (RMB), (and this does) not include accommodation. ... Nobody gives you reimbursement."

\section{The influence of a high economic burden on patient compliance}

Logistic regression suggests that TB patient treatment compliance was related to TOOP, household income, EcoBur and TLF (Table 5). After adjustment for confounding factors the main findings were that: $\mathrm{TB}$ patients with middle level household incomes were less likely to occur noncompliance than those with low household income (OR 0.355, $95 \%$ CI 0.140-0.830); those who felt EcoBur was general or high were more likely to occur non-compliance than those who felt it was low (OR 2.274, 95 \% CI 1.08110.928; OR 3.650, $95 \%$ CI 1.278-12.346, respectively); and TB patients with high TLF were more likely to occur noncompliance than those with low (OR 4.150, 95 \% CI 1.80421.999). There was no significant difference in treatment compliance resulting from the economic burdens of OOP2, IncFor or DSC.

Similar results were obtained with the untransformed continuous variables allowing for the effects of age, UEBMI, URBMI, and education, as shown in Table 4. Again, the effect of expenditure on DSC became significant.

Qualitative findings suggest that, for some patients, even the burden of transport costs can influence their treatment compliance, especially for families with more than one TB patient.

"... (The) travel cost is high, (and) influenced me (in terms of compliance)"

"There is a family, all (have) tuberculosis. If they were examined, in fact, they could be cured, but (because they) don't (have) money they are unwilling to travel (for treatment)."

\section{Discussion}

In this study, we found that age, education level, household income and patients' subjective assessment whether TB causes a heavy burden to their family are significant different between group compliance and non-compliance. In consistence with previous studies, we also got the similar result that patients who are elderly, low education level are more likely to non-compliance to TB treatment $[8,9,14,15]$. The elderly and low education level patients are more likely to have a limited ability to get and understand related TB knowledge. This cue that except the chemotherapy, a humanist intervention or assistance may be needed.

Compared with direct medical costs, the non-medical costs, dietary supplement costs and indirect costs were not high. This finding is not consistent with other studies,

Table 4 Direct and indirect costs as \% of household income of TB patients*

\begin{tabular}{|c|c|c|c|c|c|c|}
\hline & \multicolumn{2}{|l|}{ Compliant } & \multicolumn{2}{|c|}{ Non-compliant } & \multirow[t]{2}{*}{$p$-value** } & \multirow[t]{2}{*}{$p$-value*** } \\
\hline & Mean & Median [IQR] & Mean & Median [IQR] & & \\
\hline TOOP & 71.74 & $20[7.67-50]$ & 248.89 & $36.25[15.83-158.33]$ & 0.001 & 0.006 \\
\hline OOP2 & 47.33 & $13.12[5.17-37.35]$ & 164.43 & $20.23[7.91-93.66]$ & $<0.001$ & 0.058 \\
\hline TLF & 8.38 & $1.63[0.32-6.52]$ & 49.17 & $6.29[2-22.5]$ & 0.001 & 0.003 \\
\hline IncFor & 1.96 & $0[0-0]$ & 0.44 & $0[0-0]$ & 0.874 & 0.697 \\
\hline DSC & 2.46 & $1[0.5-2.26]$ & 4.67 & $4.29[2.04-6.94]$ & 0.009 & 0.019 \\
\hline Household income & 31336.52 & $22000[8000-41000]$ & 19681.94 & $7860[2000-24500]$ & 0.056 & $<0.001$ \\
\hline
\end{tabular}

*The variable is same with variable shown in Tables 3 and 5, but have not been transformed into categorical variable

**This value calculated by ANOVA based on log transformation

***This value calculated by ANCOVA based on log transformation, the covariate was Age, UEBMI, URBMI, and Education 
Table 5 Logistic regression of economic burden's effect on TB patients' compliance with OR and adjusted OR

\begin{tabular}{|c|c|c|c|c|}
\hline & \multicolumn{2}{|c|}{ Pre-adjusted } & \multicolumn{2}{|c|}{ Adjusted $^{a}$} \\
\hline & $p$-value & OR $(95 \% \mathrm{Cl})$ & $p$-value & Adjusted OR (95\% Cl) \\
\hline TOOP $(=1)$ & 0.032 & $2.811(1.207-13.971)$ & 0.07 & $2.406(0.939-12.244)$ \\
\hline $\mathrm{OOP} 2(=1)$ & 0.096 & $2.034(0.926-7.199)$ & 0.18 & $1.822(0.766-6.013)$ \\
\hline $\operatorname{TLF}(=1)$ & 0.003 & $4.545(1.850-21.999)$ & 0.001 & $4.150(1.804-21.999)$ \\
\hline $\operatorname{IncFor~}(=1)$ & 0.396 & $0.580(0.000-1.697)$ & 0.653 & $0.829(0.000-2.754)$ \\
\hline DSC $(=1)$ & 0.094 & $3.040(0.689-20.589)$ & 0.155 & $2.622(0.500-25.815)$ \\
\hline \multicolumn{5}{|l|}{ Household income } \\
\hline \multicolumn{5}{|l|}{ Low (lowest 25 \%) } \\
\hline Middle (medium 50 \%) & 0.001 & $0.309(0.121-0.657)$ & 0.011 & $0.355(0.140-0.830)$ \\
\hline High (top $25 \%$ ) & 0.008 & $0.286(0.061-0.709)$ & 0.155 & $0.419(0.066-1.435)$ \\
\hline \multicolumn{5}{|l|}{ EcoBur } \\
\hline \multicolumn{5}{|l|}{ Low } \\
\hline General & 0.047 & $2.300(1.091-8.987)$ & 0.037 & $2.274(1.081-10.928)$ \\
\hline High & 0.002 & $3.333(1.113-10.989)$ & 0.001 & $3.650(1.278-12.346)$ \\
\hline
\end{tabular}

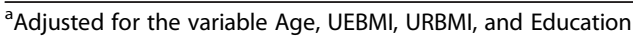

which often indicate that the main burden arises from transport, diet supplements and loss of income [17, 46]. Explanation is that most of the patients were located in rural areas with incomes mainly coming from farming or self-employment (Table 2). The time required for diagnosis and treatment have little impact on the time available for work and the food for diet supplementation usually be home grown.

Though the free-TB service policy, patients have to pay a high expenditure on diagnosis and treatment. Even though covered by insurance, this expenditure doesn't reduce too much. In the integrated model, TB patients can only be diagnosed and treated under the free treatment policy in the designated hospital. The free treatment policy just covered first-line anti-TB drugs, TB sputum smears and cultures, and X-ray examinations for the first and last months $[16,21,23,24,51]$, and these items' profit is low. Driven by the revenue, doctors may over-prescript additional drugs and test $[16,33]$. As the qualitative results showed, overuse of liver protection drugs and CT test is not uncommon. And also previous studies revealed that providers have the motivation to use second-line antiTB drugs [16, 21, 26]. All these overused items neither covered by the free policy, nor by the insurance, resulting in high patient OOP medical expenditure. A systematic review based on 85 research articles found no reliable evidence to support prescription of drugs protects the liver [52]. studies also reported that NCMS did not reduce patient out-ofpocket costs per episode [31, 53, 54]. All of these indicated that improving providers' salary system, expanding insurance's coverage is needed.

This study revealed a very high economic burden for TB patients in China, in line with prior studies [16, 28, 29, 55].
Almost $68 \%$ of TB patients reported catastrophic health expenditure (Table 3), much higher than the average for China [43, 44]. Patients with low household incomes or who felt that the economic burden was high were more likely to occur non-compliance (Table 5). These findings lend support to the argument that there is an association between TB and poverty and suggests that TB patients still face economic barriers in seeking diagnosis and treatment $[20,28,30]$.

Contrary to expectations, the quantitative analysis suggests that a high economic burden did not in itself result in poor compliance (Table 5). This finding has two possible explanations. First, a sunk cost effect probably exists in relation to seeking diagnosis and treatment. If a patient has spent a lot of money at early stage, he or she may continue to seek treatment, to avoid that expenditure becoming a sunk cost, even borrowing money or selling property to continue treatment. Second, in the process of calculating the economic burden, we only include the actual costs, not the anticipated costs. Patients with low household incomes may interrupt their treatment because they expect that further treatment will become unaffordable [9]. Such patients would certainly feel that the economic burden of treatment was very high. And these reasons can also explain why we can't get a significant result from the test of direct and indirect costs between compliant patients and non-compliant patients.

Even the costs related to transport, accommodation and food could lead to catastrophic expenditure (Table 3). And the results from both from quantitative and qualitative studies demonstrate that the burden from costs on transport, lodging and food had a substantial effect on treatment 
compliance, in line with Tadesse's study [3].This also lend supports to the hypothesis above. In China, under the free policy, providers are supposed to educate TB patients related knowledge before chemotherapy. Previous studies indicated several points: lack of knowledge about anti-TB treatment was associated with higher non-compliance rates $[8,13]$; some patients still confused about treatment regimen after health education [8]; adverse reactions contribute to non-compliance $[15,21]$. For patients with low household income, if adverse reactions occurred or symptoms relieved and can't convenient keep in touch with doctors, travelling long distances to a health care facility at considerable expense will challenge their willingness to continue treatment $[3,16]$. Another situation is that as patients have to bring back their medicine monthly, the high cost of transport, lodging and food really impede them from doing so.

What can we do to improve TB patients' compliance? We suggest we can through two aspects to influence patients' behavior: knowledge and economic burden. As we discussed before, for patients, transport, accommodation and food costs can be a barrier to keep in touch with doctors. So one of the useful ways is to develop mobile phone based intervention, as several studies already emphasize this intervention's potential effectiveness [56-58]. Another way is to expand the current package to cover patients' transport, accommodation and food costs or offer related economic assistance. Previous studies indicated that lack of knowledge about antiTB treatment was associated with higher non-compliance rates $[8,13]$, and some patients still confused about treatment regimen after health education [8]; we found that patients who are elderly, low education level are more likely to non-compliance to TB treatment. This implied that a humanist intervention tailored by these factors may be helpful.

For economic burden, no matter actually happened burden or anticipated burden, an experience-based opinion is that due to the free-TB service policy, the economic burden caused by OOP2 just happened when patients already played a visit to doctor, otherwise they wouldn't know or anticipate whether the burden is high. According to the above discussion, improving doctors' salary system to cut off the revenue-oriented incentive, and expanding current insurance's coverage is useful. Chinese insurance is a multilevel system. In our study, the actually happened economic burden is high. To enhance the cooperation between different level's insurance, for instance between basic insurance and critical illness insurance or assistance, is necessary.

\section{Limitations}

The proportion of non-adherence in our study is not high compared with that were reported in previous studies [8-11], and much of the difference may be due to differences in study design and definition of nonadherence to anti-TB treatment. As we want to evaluate economic burden's effect, we identified non-compliant patients as those who interrupted or stopped treatment (if not because of any adverse reactions) or refused treatment. We identified patients from a list of TB patients compiled at the time that each patient began their $\mathrm{TB}$ regimen. Some of patients may not be on this list, especially those located in remote rural areas, who are more likely to be non-compliant because of the long distance to the health care facility. In addition, suspected TB patients were not included in our study. So, as a matter of fact, the situation is more serious, and the effect of economic burden on compliance may therefore be underestimated.

In our study, we included three sample cities, located in the Eastern, Middle and Western regions of China, respectively. Background of the studied setting is different more or less, and the more appropriate analysis is disaggregate patients by the three regions. Due to the limitation of sample size of non-compliance patients, this method will come with high risk of deviation. Further study with more sample size is needed to explore inter-regional difference.

To avoid the influence of inaccurate data and extreme values and to simplify interpretation of the regression results, we transformed several continuous variable to ordered category form, though this had little impact on the results. However, recall bias will still almost certainly have influenced the findings. The economic impact of income foregone was very limited compared with the results from other studies [17, 29]. It is possible that this concept was not well understood by respondents.

\section{Conclusion}

Our results lend weight to the argument that there is a link between $\mathrm{TB}$ and poverty and that TB patients continue to face economic barriers in seeking diagnosis and treatment. TB patients with low household incomes or who feel that the economic burden of treatment is high are more likely to have poor compliance. As indicated above, the number of TB patients in China is very large. The provision of free anti-TB drugs has been a valuable step forward but to improve the coverage and effectiveness of control programs for TB. We suggest that the useful way is to develop mobile phone based intervention or offer patients transport, accommodation and food economic assistance to break down the barrier of keeping in touch with doctors. Another way is to improve doctors' salary system to cut off the revenue-oriented incentive, expand current insurance's coverage, and enhance cooperation between different level's insurance. 


\section{Additional file}

\section{Additional file 1: Multilingual abstracts in the six official working} languages of the United Nations. (DOC $21 \mathrm{~kb}$ )

\section{Abbreviations}

CDC: Centre for Disease Control; DOT: Direct observation of treatment; DSC: Dietary supplement costs as a percent of household income; EcoBur: Patients' subjective assessment whether TB causes a heavy burden to their family; FGDs: Focus group discussions; GDP: Gross domestic product; IncFor: Income foregone due to the illness as a percent of household income; NCMS: New Cooperative Medical Scheme; NHPFC: National Health and Family Planning Commission of the People's Republic of China; OOP: Out-of-pocket payment; OOP2: Out-of-pocket payment for diagnosis and treatment as a percent of household income; PPS: ProbabilityProportional-to-Size Sampling; TB: Tuberculosis; TLF: Travel, lodging and food costs as a percent of household income; TOOP: Total out-of-pocket payment, including direct medical costs, direct non-medical costs, and indirect costs, as a percent of household income; UEBMI: Urban Employee Basic Medical Insurance; URBMI: Urban Resident Basic Medical Insurance; WHO: World Health Organization.

\section{Competing interests}

The authors declare that they have no competing interests.

\section{Authors' contributions}

SC, YP, LX and $\mathrm{HZ}$ were the main authors of the manuscript and were involved in all aspects of the study. SC and QL were involved in the data collection and analysis. $\mathrm{HL}$ and $\mathrm{LY}$ participated in the reviewing and editing of the paper. All authors read and approved the final manuscript.

\section{Acknowledgements}

The study upon which this paper was written is part of the large program entitled "China National Health and Family Planning Commission and the Gates Foundation TB Project", a collaboration between the Government of China and the Melinda and Bill Gates Foundation (Grant No. 51914), and implemented by the China Center of Disease Control and Prevention (CDC). The Duke Global Health Institute, USA/Duke Kunshan University in China, and Nanjing Medical University, Huazhong University of Science and Technology and Xi'an Jiaotong University in China were contracted by the Foundation and China CDC to undertake the baseline survey, and monitoring and evaluation of innovative financial models of TB/MDRTB control and care in China. In addition, the authors express their deep appreciation to all the staffs in the research areas, as well as the Chinese Center for Disease Control and Prevention for allowing this study to be conducted in the selected health facilities. The authors would also like to acknowledge Chee-Ruey Hsieh, Professor of Duke Kunshan University, and Shenglan Tang, Professor of Duke University, for their critical review and comments on the manuscript.

This study was also supported by the project "Research on Economic Risk of Major Diseases and the Protection Effect Model of Rural Residents in the Central and Western Regions of China" supported by the National Natural Science Foundation of China(Grant No. 71203068).

\section{Author details}

${ }^{1}$ The Jockey Club School of Public Health and Primary Care, The Chinese University of Hong Kong, Hong Kong, China. ${ }^{2}$ National Center for TB Control and Prevention, China CDC, Beijing, PR China. ${ }^{3}$ The Third Affiliated Hospital, Sun Yat-sen University, Guangzhou, China. ${ }^{4}$ Duke Global Health Institute, Duke University, Durham, NC, USA. ${ }^{5}$ Global Health Research Center, Duke Kunshan University, Kunshan, China. ${ }^{6}$ School of Medicine and Health Management, Huazhong University of Science and Technology, Wuhan, China. ${ }^{7}$ Institute of Development Studies, Sussex University, Brighton, UK. ${ }^{8}$ Chinese Center for Disease Control and Prevention, Beijing, PR China.

Received: 22 July 2015 Accepted: 10 October 2015 Published online: 28 October 2015

\section{References}

1. WHO. Global Tuberculosis Report 2014. Geneva: World Health Organization; 2014.
2. WHO. Introducing the WHO End TB Strategy. Geneva: World Health Organization; 2015.

3. Tadesse T, Demissie M, Berhane $Y$, Kebede $Y$, Abebe M. Long distance travelling and financial burdens discourage tuberculosis DOTs treatment initiation and compliance in Ethiopia: a qualitative study. BMC Public Health. 2013;13:424. doi:10.1186/1471-2458-13-424

4. van den Boogaard J, Msoka E, Homfray M, Kibiki GS, Heldens JJ, Felling AJ, et al. An exploration of patient perceptions of adherence to tuberculosis treatment in Tanzania. Qualitative Health Res. 2012;22(6):835-45. doi:10.1177/1049732312438968.

5. Ayisi JG, van't Hoog AH, Agaya JA, McHembere W, Nyamthimba PO, Muhenje $\mathrm{O}$, et al. Care seeking and attitudes towards treatment compliance by newly enrolled tuberculosis patients in the district treatment programme in rural western Kenya: a qualitative study. BMC Public Health. 2011;11:515. doi:10.1186/1471-2458-11-515.

6. Munro SA, Lewin SA, Smith HJ, Engel ME, Fretheim A, Volmink J. Patient adherence to tuberculosis treatment: a systematic review of qualitative research. PLoS medicine. 2007;4(7):e238. doi:10.1371/journal.pmed.0040238.

7. Corbett EL, Bandason T, Cheung YB, Munyati S, Godfrey-Faussett P, Hayes R, et al. Epidemiology of tuberculosis in a high HIV prevalence population provided with enhanced diagnosis of symptomatic disease. PLoS Med. 2007;4(1), e22. doi:10.1371/journal.pmed.0040022.

8. Tang $Y$, Zhao M, Wang Y, Gong Y, Yin X, Zhao A, et al. Non-adherence to anti-tuberculosis treatment among internal migrants with pulmonary tuberculosis in Shenzhen. China: a cross-sectional study BMC public health. 2015;15:474. doi:10.1186/s12889-015-1789-z.

9. Zhou C, Chu J, Liu J, Gai Tobe R, Gen H, Wang X, et al. Adherence to tuberculosis treatment among migrant pulmonary tuberculosis patients in Shandong, China: a quantitative survey study. PloS one. 2012;7(12), e52334. doi:10.1371/journal.pone.0052334.

10. Hu D, Liu X, Chen J, Wang Y, Wang T, Zeng W, et al. Direct observation and adherence to tuberculosis treatment in Chongqing, China: a descriptive study. Health policy and planning. 2008;23(1):43-55. doi:10.1093/heapol/czm038.

11. Yao S, Huang WH, van den Hof S, Yang SM, Wang XL, Chen W, et al. Treatment adherence among sputum smear-positive pulmonary tuberculosis patients in mountainous areas in China. BMC health services research. 2011;11:341. doi:10.1186/1472-6963-11-341.

12. Xu W, Lu W, Zhou Y, Zhu L, Shen H, Wang J. Adherence to anti-tuberculosis treatment among pulmonary tuberculosis patients: a qualitative and quantitative study. BMC health services research. 2009;9:169. doi:10.1186/1472-6963-9-169.

13. Driver CR, Matus SP, Bayuga S, Winters Al, Munsiff SS. Factors associated with tuberculosis treatment interruption in New York City. Journal of public health management and practice : JPHMP. 2005;11(4):361-8.

14. Zhu M, Wang J, Dib HH, Wang Z. Enhancing the management of cross-regional transfer of floating tuberculosis cases by active follow-up and communication. European journal of public health. 2012;22(4):577-82. doi:10.1093/eurpub/ckr154.

15. Liang L, Wu Q, Gao L, Hao Y, Liu C, Xie Y, et al. Factors contributing to the high prevalence of multidrug-resistant tuberculosis: a study from China. Thorax. 2012;67(7):632-8. doi:10.1136/thoraxjnl-2011-200018.

16. Long Q, Smith H, Zhang T, Tang S, Garner P. Patient medical costs for tuberculosis treatment and impact on adherence in China: a systematic review. BMC public health. 2011;11:393. doi:10.1186/1471-2458-11-393.

17. Kik SV, Olthof SP, de Vries JT, Menzies D, Kincler N, van Loenhout-Rooyakkers J, et al. Direct and indirect costs of tuberculosis among immigrant patients in the Netherlands. BMC public health. 2009;9:283. doi:10.1186/1471-2458-9-283.

18. Liu X, Thomson R, Gong Y, Zhao F, Squire SB, Tolhurst R, et al. How affordable are tuberculosis diagnosis and treatment in rural China? An analysis from community and tuberculosis patient perspectives. Tropical medicine \& international health : TM \& IH. 2007;12(12):1464-71. doi:10.1111/ j.1365-3156.2007.01953.x.

19. Jackson S, Sleigh AC, Wang GJ, Liu XL. Poverty and the economic effects of TB in rural China. The international journal of tuberculosis and lung disease : the official journal of the International Union against Tuberculosis and Lung Disease. 2006;10(10):1104-10.

20. Zhang T, Tang S, Jun G, Whitehead M. Persistent problems of access to appropriate, affordable TB services in rural China: experiences of different socio-economic groups. BMC public health. 2007;7:19. doi:10.1186/14712458-7-19.

21. Xu WG, Lu W, Zhou Y, Zhu LM, Shen HB, Wang JM. Adherence to anti-tuberculosis treatment among pulmonary tuberculosis patients: a qualitative and quantitative study. BMC health services research. 2009;9. doi:Artn 169 10.1186/1472-6963-9-169. 
22. Wang L, Liu J, Chin DP. Progress in tuberculosis control and the evolving public-health system in China. Lancet. 2007;369(9562):691-6. doi:10.1016/ S0140-6736(07)60316-X.

23. Wei $X$, Chen J, Chen P, Newell JN, Li H, Sun C, et al. Barriers to TB care for rural-to-urban migrant TB patients in Shanghai: a qualitative study. Tropical medicine \& international health : TM \& IH. 2009;14(7):754-60. doi:10.1111/ j.1365-3156.2009.02286.x.

24. Pan HQ, Bele S, Feng Y, Qiu SS, Lu JQ, Tang SW, et al. Analysis of the economic burden of diagnosis and treatment of tuberculosis patients in rural China. The international journal of tuberculosis and lung disease : the official journal of the International Union against Tuberculosis and Lung Disease. 2013;17(12):1575-80. doi:10.5588/ijtld.13.0144

25. Liu Q, Smith H, Wang Y, Tang S, Wang Q, Garner P. Tuberculosis patient expenditure on drugs and tests in subsidised, public services in China: a descriptive study. Tropical medicine \& international health : TM \& IH. 2010;15(1):26-32. doi:10.1111/j.1365-3156.2009.02427.x.

26. Wei X, Zou G, Walley J, Yin J, Lonnroth K, Uplekar M, et al. China tuberculosis policy at crucial crossroads: comparing the practice of different hospital and tuberculosis control collaboration models using survey data. PloS one. 2014;9(3), e90596. doi:10.1371/journal.pone.0090596.

27. Liu M, Zhang Q, Lu M, Kwon CS, Quan H. Rural and urban disparity in health services utilization in China. Medical care. 2007;45(8):767-74. doi:10.1097/ MLR.0b013e3180618b9a.

28. Mauch V, Bonsu F, Gyapong M, Awini E, Suarez P, Marcelino B, et al. Free tuberculosis diagnosis and treatment are not enough: patient cost evidence from three continents. The international journal of tuberculosis and lung disease : the official journal of the International Union against Tuberculosis and Lung Disease. 2013;17(3):381-7. doi:10.5588/ijtld.12.0368.

29. Umar NA, Fordham R, Abubakar I, Bachmann M. The indirect cost due to pulmonary Tuberculosis in patients receiving treatment in Bauchi StateNigeria. Cost effectiveness and resource allocation : C/E. 2012;10(1):6. doi:10.1186/1478-7547-10-6.

30. WHO. Addressing poverty in TB control. Options for National TB Control Programmes. 2005th ed. Geneva: World Health Organization; 2005.

31. Wei X, Zou G, Yin J, Walley J, Zhang X, Li R, et al. Effective reimbursement rates of the rural health insurance among uncomplicated tuberculosis patients in China. Tropical medicine \& international health : TM \& $1 \mathrm{H}$. 2015;20(3):304-11. doi:10.1111/tmi.12438.

32. Qiu S, Pan H, Zhang S, Peng X, Zheng $X, X u$ G, et al. Is tuberculosis treatment really free in China? A study comparing two areas with different management models. PloS one. 2015;10(5):e0126770. doi:10.1371/journal.pone.0126770.

33. Zhan S, Wang L, Yin A, Blas E. Revenue-driven in TB control-three cases in China. Int J Health Plann Manag. 2004;19 Suppl 1:S63-78. doi:10.1002/hpm.778.

34. Qing-ping $S$, Xiao-dong J, Feng D, Yan L, Mei-ling $Y$, Jin-xiu $Z$, et al. Consequences, measurement, and evaluation of the costs associated with adverse drug reactions among hospitalized patients in China. BMC Health Serv Res. 2014;14:73. doi:10.1186/1472-6963-14-73.

35. Chiatti C, Bustacchini S, Furneri G, Mantovani L, Cristiani M, Misuraca C, et al, The economic burden of inappropriate drug prescribing, lack of adherence and compliance, adverse drug events in older people: a systematic review. Drug Saf. 2012;35 Suppl 1:73-87. doi:10.1007/bf03319105.

36. Jang D, Mattila AS, Bai B. Restaurant membership fee and customer choice: The effects of sunk cost and feelings of regret. Int J Hosp Manag. 2007;26(3):687-97.

37. McElhinney D, Proctor T. Concept of entrapment and decision-making. Manag Decis. 2005;2(43):189-202.

38. Christensen-Szalanski JJ, Northcraft GB. Patient compliance behavior: the effects of time on patients' values of treatment regimens. Soc Sci Medicine. 1985:21(3):263-73.

39. Grellety E, Luquero FJ, Mambula C, Adamu HH, Elder G, Porten K. Observational bias during nutrition surveillance: results of a mixed longitudinal and crosssectional data collection system in Northern Nigeria. PloS One. 2013;8(5), e62767. doi:10.1371/journal.pone.0062767.

40. Auld AF, Mbofana F, Shiraishi RW, Alfredo C, Sanchez M, Ellerbrock TV, et al. Incidence and determinants of tuberculosis among adults initiating antiretroviral therapy-Mozambique, 2004-2008. PloS One. 2013;8(1):e54665. doi:10.1371/ journal.pone.0054665.

41. Loyalka P, Liu L, Chen G, Zheng X. The cost of disability in china. Demography. 2014:51(1):97-118. doi:10.1007/s13524-013-0272-7.

42. Wang $H$, Ye F, Wang $Y$, Huntington D. Economic impact of maternal death on households in rural china: a prospective cohort study. Plos One. 2013;8(10):e76624. doi:10.1371/journal.pone.0076624.
43. Meng Q, Xu L, Zhang Y, Qian J, Cai M, Xin Y, et al. Trends in access to health services and financial protection in China between 2003 and 2011: a crosssectional study. Lancet. 2012;379(9818):805-14. doi:10.1016/s0140-6736(12)60278-5.

44. Li Y, Wu Q, Xu L, Legge D, Hao Y, Gao L, et al. Factors affecting catastrophic health expenditure and impoverishment from medical expenses in China: policy implications of universal health insurance. Bull World Health Organ. 2012;90(9):664-71. doi:10.2471/BLT.12.102178.

45. Shi W, Chongsuvivatwong V, Geater A, Zhang J, Zhang H, Brombal D. Effect of household and village characteristics on financial catastrophe and impoverishment due to health care spending in Western and Central Rural China: A multilevel analysis. Health Res Policy Syst. 2011;9:16. doi:10.1186/ 1478-4505-9-16.

46. Aspler A, Menzies D, Oxlade O, Banda J, Mwenge L, Godfrey-Faussett P, et al. Cost of tuberculosis diagnosis and treatment from the patient perspective in Lusaka. Zambia Int J Tuberc Lung Dis. 2008;12(8):928-35.

47. Waters HR, Anderson GF, Mays J. Measuring financial protection in health in the United States. Health policy. 2004;69(3):339-49. doi:10.1016/j.healthpol.2004.01.003.

48. Ranson MK. Reduction of catastrophic health care expenditures by a community-based health insurance scheme in Gujarat, India: current experiences and challenges. Bull World Health Organ. 2002;80(8):613-21.

49. Becerra MC, Appleton SC, Franke MF, Chalco K, Arteaga F, Bayona J, et al. Tuberculosis burden in households of patients with multidrug-resistant and extensively drug-resistant tuberculosis: a retrospective cohort study. Lancet. 2011;377(9760):147-52. doi:10.1016/S0140-6736(10)61972-1.

50. Smith J, Firth J. Qualitative data analysis: the framework approach. Nurse Res. 2011;18(2):52-62. doi:10.7748/nr2011.01.18.2.52.c8284

51. Liu Q, Smith H, Wang Y, Tang SL, Wang QL, Garner P. Tuberculosis patient expenditure on drugs and tests in subsidised, public services in China: a descriptive study. Trop Med Int Health. 2010;15(1):26-32. doi:10.1111/j.13653156.2009.02427.x.

52. Liu Q, Garner P, Wang Y, Huang B, Smith H. Drugs and herbs given to prevent hepatotoxicity of tuberculosis therapy: systematic review of ingredients and evaluation studies. BMC Public Health. 2008:8:365. doi:10.1186/1471-2458-8-365

53. Babiarz KS, Miller G, Yi H, Zhang L, Rozelle S. New evidence on the impact of China's New Rural Cooperative Medical Scheme and its implications for rural primary healthcare: multivariate difference-in-difference analysis. BMJ. 2010;341:c5617. doi:10.1136/bmj.c5617.

54. Meng Q, Xu K. Progress and challenges of the rural cooperative medical scheme in China. Bull World Health Organ. 2014;92(6):447-51. doi:10.2471/ BLT.13.131532.

55. Rouzier VA, Oxlade O, Verduga R, Gresely L, Menzies D. Patient and family costs associated with tuberculosis, including multidrug-resistant tuberculosis, in Ecuador. Int J Tuberc Lung Dis. 2010;14(10):1316-22.

56. Tola HH, Tol A, Shojaeizadeh D, Garmaroudi G. Tuberculosis Treatment NonAdherence and Lost to Follow Up among TB Patients with or without HIV in Developing Countries: A Systematic Review. Iran J Public Health. 2015;44(1):1-11.

57. Nglazi MD, Bekker LG, Wood R, Hussey GD, Wiysonge CS. Mobile phone text messaging for promoting adherence to anti-tuberculosis treatment: a systematic review. BMC Infect Dis. 2013;13:566. doi:10.1186/1471-2334-13-566.

58. Kunawararak $P$, Pongpanich $S$, Chantawong $S$, Pokaew $P$, Traisathit $P$, Srithanaviboonchai $K$, et al. Tuberculosis treatment with mobile-phone medication reminders in northern Thailand. Southeast Asian J Trop Med Public Health. 2011;42(6):1444-51

\section{Submit your next manuscript to BioMed Central and take full advantage of:}

- Convenient online submission

- Thorough peer review

- No space constraints or color figure charges

- Immediate publication on acceptance

- Inclusion in PubMed, CAS, Scopus and Google Scholar

- Research which is freely available for redistribution 